\title{
Article
}

\section{Evaluation of Accuracy of Traffic Flow Generation in SUMO}

\author{
Xiaoyi Ma (D), Xiaowei Hu*(D), Thomas Weber (D) and Dieter Schramm (D) \\ Department of Mechatronics, University of Duisburg-Essen, 47047 Duisburg, Germany; \\ xiaoyi.ma@uni-due.de (X.M.); thomas.markus.weber@uni-due.de (T.W.); dieter.schramm@uni-due.de (D.S.) \\ * Correspondence: xiaowei.hu@uni-due.de
}

\section{check for} updates

Citation: Ma, X.; Hu, X.; Weber, T.; Schramm, D. Evaluation of Accuracy of Traffic Flow Generation in SUMO. Appl. Sci. 2021, 11, 2584. https:// doi.org/10.3390/app11062584

Academic Editor: Juan-Carlos Cano

Received: 22 February 2021

Accepted: 11 March 2021

Published: 14 March 2021

Publisher's Note: MDPI stays neutral with regard to jurisdictional claims in published maps and institutional affiliations.

Copyright: (C) 2021 by the authors Licensee MDPI, Basel, Switzerland. This article is an open access article distributed under the terms and conditions of the Creative Commons Attribution (CC BY) license (https:/ / creativecommons.org/licenses/by/ $4.0 /)$.

\begin{abstract}
A traffic simulation of the Jianghan Zone in Wuhan, China was carried out. In order to simulate genuine traffic flow without traditional hard-to-implement data collection methods, geographic population distribution data were gathered from the public information and traffic flow was generated by ActivityGen in SUMO (Simulation of Urban Mobility). For the sake of discovering the accuracy of the simulated traffic, real-time road condition and traffic prediction based on previous data on same time of each road in this area was compared. The results show that traffic flow generated from geographic population distribution data has referential meanings and with more detailed model classification, simulated traffic data can be closer to real conditions. This may offer a new way to generate traffic flow for researchers working in traffic simulation area. Further improvement of the accuracy in traffic flow generation by geographic population needs to pay more attention on special places like hospital and train stations.
\end{abstract}

Keywords: traffic simulation; geographic population distribution; SUMO

\section{Introduction}

The Chinese automotive market accounted for around 30\% of global passenger car sales since 2016 [1,2]. For new energy vehicles, the percentage is over $50 \%$, and it is continuously increasing. The robust growth brings social problems such as the traffic jams, global warming, and other environmental issues. Nonetheless, a social experiment is not only risky but costly as well, and it is difficult to conduct to resolve such problems.

A virtual experiment using traffic simulation provides an effective way to solve the existing and coming problems. In building traffic simulation of the real world, two elements are the most important: a detailed road network and the corresponding traffic demand. Other aspects also affect the accuracy of simulation, such as the road choice algorithm [3], the selection of simulation software packages [4], traffic light strategies [5], etc. Most simulation software packages can import an open-source city map as a road network [4], however, the corresponding real traffic demands are not easy to obtain.

In imitating real-world traffic, traffic data play an important role. Some seek the rules of real data to build a model, some verify their simulation results with real data. Most present research works collect real traffic demand through three methods: trajectory data from camera, speed data from induction loop detector, and floating car data (FCD) from data loggers [6]. Due to increasing strict privacy policy, it is more and more difficult to obtain permission for installing cameras on public roads. Induction loop detectors have similar problems in installing, and to pave induction loops on each lane is an additional and often impossible amount of work for researching. In contrast, floating car data is a costeffective way to gather accurate traffic data. However, the reliability and representativeness of traffic flow information based on FCD highly depends on the percentage of floating cars participating in the traffic flow $[7,8]$. On an expressway the density of floating vehicles should be at least $5 \%$ of all vehicles [9]. To install data loggers on $5 \%$ of all vehicles on road is not easily reachable in real data collection work. 
How to collect real traffic data is always a problem for lots of researchers. Most research works related to the establishment of traffic scenarios benefit from cooperation with the government to obtain data sources. Kastner et al. built a real time traffic condition prognose platform in Upper Austria and Salzburg with traffic counters owned by the Upper Austrian government [10]. Bieker et al. established a traffic scenario of the city of Bologna based on a project in cooperation with the European Commission [11]. Our previous work was supported by a cooperation with the administration of the city of Duisburg and had access to traffic data like the origin-destination (OD) matrix and detector data collected from induction loops and cameras [12,13]. Shafiei et al. built a simulation-based dynamic traffic assignment model of Melbourne, Australia with detector data and OD matrix data [14]. However, it is difficult for most researchers to build and analyze traffic scenarios because the real traffic data are rarely open to the public.

Simulation of Urban Mobility (SUMO) [15] is an open-source microscopic traffic simulation software, developed by the German Aerospace Center (DLR). Compared to similar simulation software, SUMO has more possibilities of model extension with less complexity. Moreover, SUMO provides a possibility to simulate traffic through geography data. There is an attachment program of SUMO called ActivityGen. The main idea of ActivityGen is to simulate people going on and coming off duty or school. So, quite detailed data such as where the residents live and where they work or the location of schools, are indispensable. Previous studies focus on using geographical population distribution to create traffic demand. Codeca et al. [16] rebuilt a 24-h scenario of Luxembourg City with geographical population distribution, the scenario contains morning and evening rush hours, also with buses and bus stations. However, without real data comparison and adjustment the accuracy cannot be proved. Asano et al. [17] built a scenario of Kobe city in Japan using ActivityGen to generate the OD data and found, by changing the speed limit of the road, the simulated data will be closer to the traffic census data than using the default settings.

In this study, we focus on a region of 683,500 residents in Wuhan, China as a particular example, where the traffic problems are greatest in Wuhan. The traffic simulation of this region was carried out. The purpose of this work is to reproduce the actual traffic using public information on the Internet. The road network, the traffic demand and the real traffic status used for verification were all collected from public information in the Internet. In addition, the reliability of the traffic generated by geographical population distribution will be discussed in the summary and the aspects of enhancing reliability will be given.

\section{Simulation}

\subsection{Road Structure}

The region we chose in Wuhan is the Jianghan Zone, which is one of the most historic and busiest areas in Wuhan. To simulate the actual traffic of Jianghan, the road network and the traffic volume has to be reproduced. Like most kinds of simulations in these fields, Open-Street Map (OSM) was used to attain the positions and directions of the roads. In particular, nearly all of the intersections in OSM are different from the real intersections (see Figure 1), and the unrealistic isolated traffic lanes will trigger unrealistic traffic jams. In Figure 1a), the vehicles on the right side must wait for three traffic lights to pass this intersection. In the scenario of the Jianghan area, 1243 roads/edges and 562 intersections/nodes are included. The systematic inaccuracy needs to be verified manually for each road and intersection, which is an extraordinary tedious and timecostly work. In order to construct the actual road structure of Jianghan, we adjusted the intersections through street view. Despite the popularity of Google maps, AutoNavi map is used in this study because of their higher quality and more complete data in China [18]. 


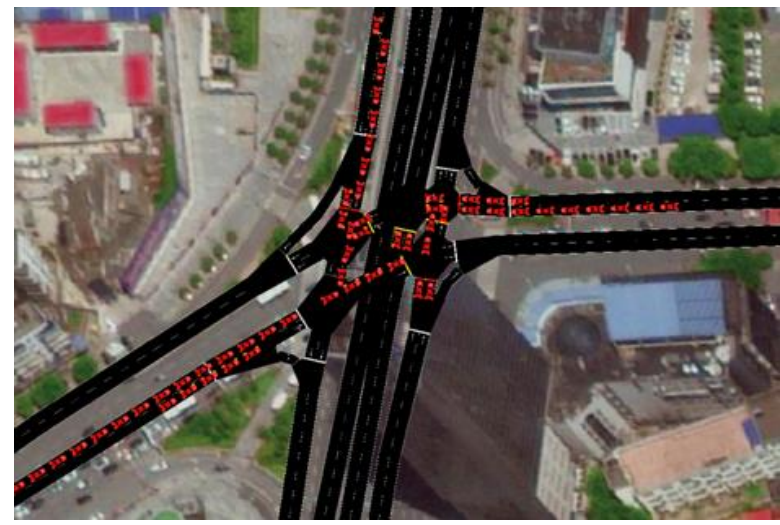

(a) Road network imported from OSM

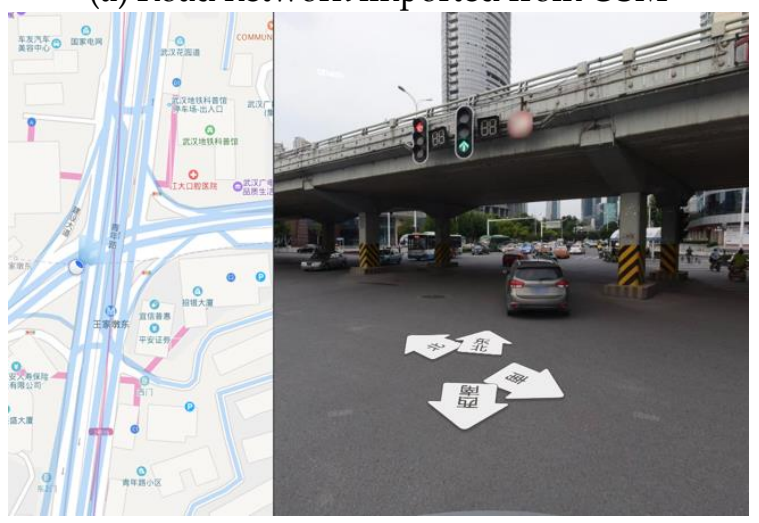

(c) Street view of the intersection

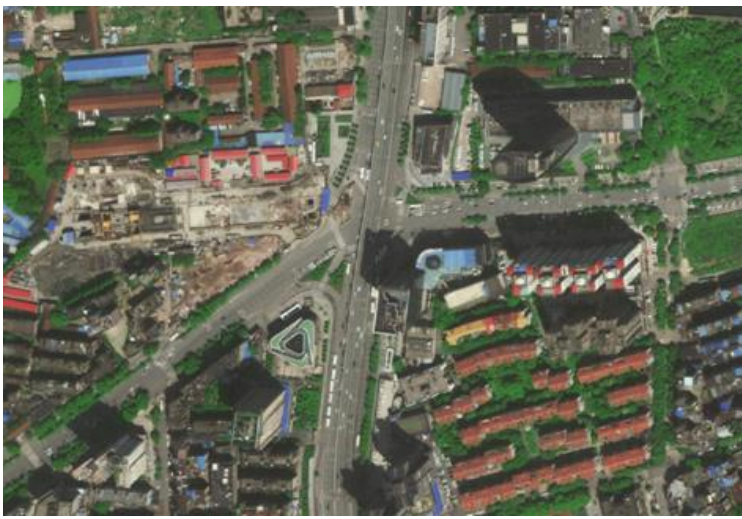

(b) Satellite map of the intersection

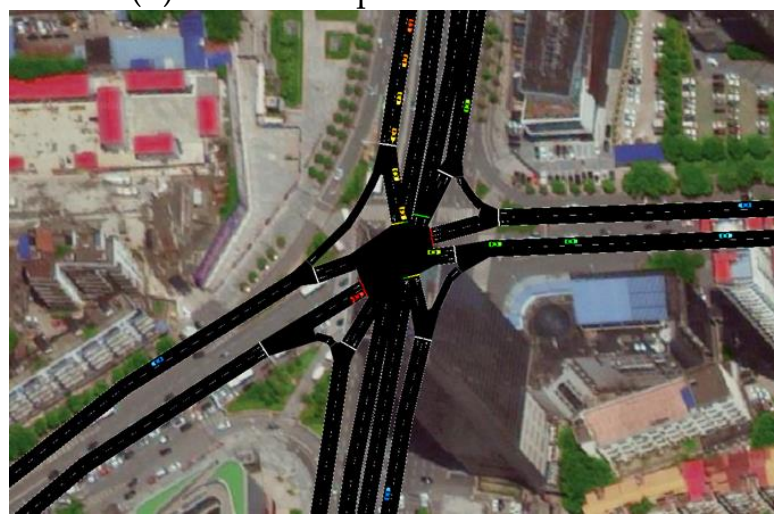

(d) Manually adjusted intersection

Figure 1. Manually adjustment according to actual road structure.

\subsection{Trip Generation}

To simulate accurate traffic demand, we should know where people live and where they work. These data were all collected from public information. According to the Chinese government demographic census [19], the population in the Jianghan Zone is 683,500 (2010), and of those, the working population is calculated from working age (1960) and the unemployment rate in Wuhan [20]. According to the educational system in China, school-age is divided into primary school age (6-12) middle school age (13-15) and high school age (16-18). The number of residents in each community can be found on different estate websites, which also provides the number of households and the vacancy rate. For example, for the Wankecheng district located between Jiangzhen Street and the third ring road in the Jianghan area, it can be found at the LIANJIA website (https:/ / wh.lianjia.com/, accessed on 12 March 2021) that the building numbers are 11 and the total number of apartments is 2906. Other information, like opening times and students' count of each school, numbers of staff in each workplace and also bus line interval time and stations are gathered through individual websites. Some of the data sources are listed in Table 1. 
Table 1. Information for generating traffic demand in ActivityGen.

\begin{tabular}{|c|c|c|}
\hline Items & Amount & Data Source \\
\hline Inhabitants & 683,500 & $\begin{array}{l}\text { Jianghan District People's } \\
\text { Government }\end{array}$ \\
\hline Number of households & 154,850 & $\begin{array}{l}\text { Hubei Provincial Bureau of } \\
\text { Statistics }\end{array}$ \\
\hline Retirement age & $50-60$ & State Council of China \\
\hline Car rate & 0.28 & $\begin{array}{l}\text { Hubei Provincial People's } \\
\text { Government }\end{array}$ \\
\hline Unemployment rate & 0.02 & $\begin{array}{l}\text { Human Resources and Social } \\
\text { Security Department of Wuhan }\end{array}$ \\
\hline Primary school age limit & $6-11$ & Ministry of Education of China \\
\hline Primary school students' number & 30,531 & Hubei Provincial Bureau of Statics \\
\hline Middle school age limit & $12-14$ & Ministry of Education of China \\
\hline Middle school students' number & 13,420 & Hubei Provincial Bureau of Statics \\
\hline High school age limit & $15-17$ & Ministry of Education of China \\
\hline High school students' number & 7537 & Hubei Provincial Bureau of Statics \\
\hline Vocational school students' number & 5527 & Hubei Provincial Bureau of Statics \\
\hline
\end{tabular}

The geographical population distribution information is written in a statistic file in the form defined by SUMO. Along with the road network file, the statistic file is generated as trip files by ActivityGen. The statistic file contains general information such as inhabitants, households, car rate, etc., population and work position distribution, school information, distribution parameters, etc. Based on the information in the statistic file, ActivityGen allocates traffic demand on the road network to form a trip file. The trip file describes when each vehicle goes from which starting point to which destination point.

In addition to commuting demand, traffic demand data also include shopping demand, entertainment demand, visiting friends or relatives, etc. These types of traffic demands are often non-directional in time and space. Therefore, these traffic demands are described as random trips in simulation. The incoming traffic and outgoing traffic of the selected road network are also described in statistic files.

As the busiest zone in the city of Wuhan, the Jianghan Zone has a population of 683,500 within 33.43 square kilometers, which makes the population density 20,445 people $/ \mathrm{km}^{2}$. This huge population density makes the difficulty of travel obvious. Fortunately, the construction of public transportation is conducted pretty well, and the public transportationsharing rate has raised close to $60 \%$ [21]. Due to the public information provided by Wuhan Transportation Committee [22], the traffic demand calculated from geographic population distribution data is verified by the total travel times of the whole city.

\subsection{Traffic Information}

The simulation utilizing SUMO was carried out by using a road network and the route data prepared by the method described above. The road network was converted by NETCONVERT, which is an attachment program of SUMO. The resulting route network is compared against the original map of the Jianghan Zone in Figure 2. 


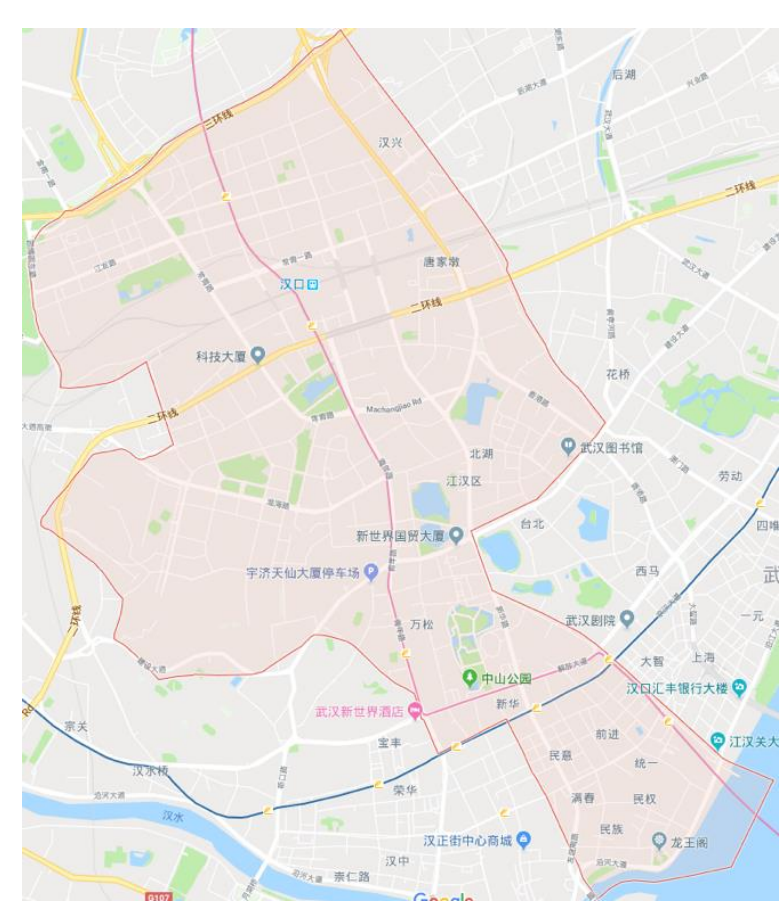

(a) Original map of Jianghan area

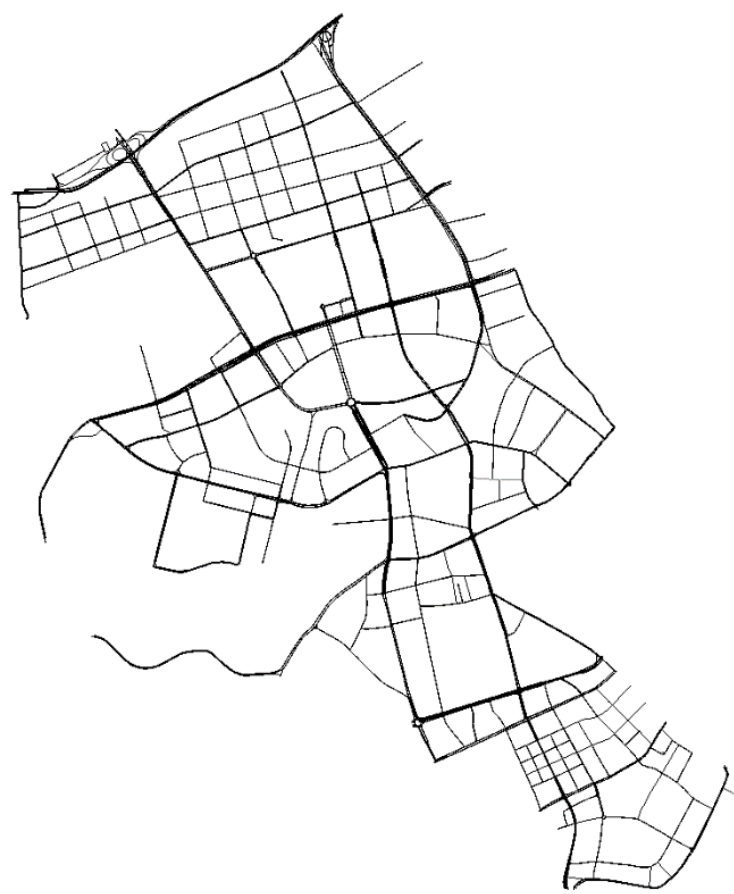

(b) Road network of Jianghan area

Figure 2. (a) Original Map and (b) abstracted road network of Jianghan Zone.

We used ActigvityGen to generate trip files in SUMO according to geographic population data mentioned above, and then it was necessary to construct a route file. In this study, the DUAROUTER, which is another attachment program of SUMO, was applied to decide the route of the vehicle. This program inspects the minimum travelling time path between origin and destination written by the trip file using Dijkstra [23] method. We assumed that people use an intelligent navigation system to find their quickest way to work and going home, the same as the Dijkstra method. To optimize the distribution of trips, we used dynamic user equilibrium recommended by SUMO. The dynamic user equilibrium is based on the principle that through multiple iterations, all the vehicles will find the most timesaving way. The route file generated from geographical population distribution was iterated with a python program, also a sub-program provided by SUMO. It generates a new route file after each step of iteration. Then, based on the new generated route file, another step of iteration is launched. After 100 time-iterations, we chose the best trip distribution as our route file. The flow chart of the process of building the simulation and the data type have been used are shown in Figure 3, where the data in blue boxes were obtained from the Internet. 


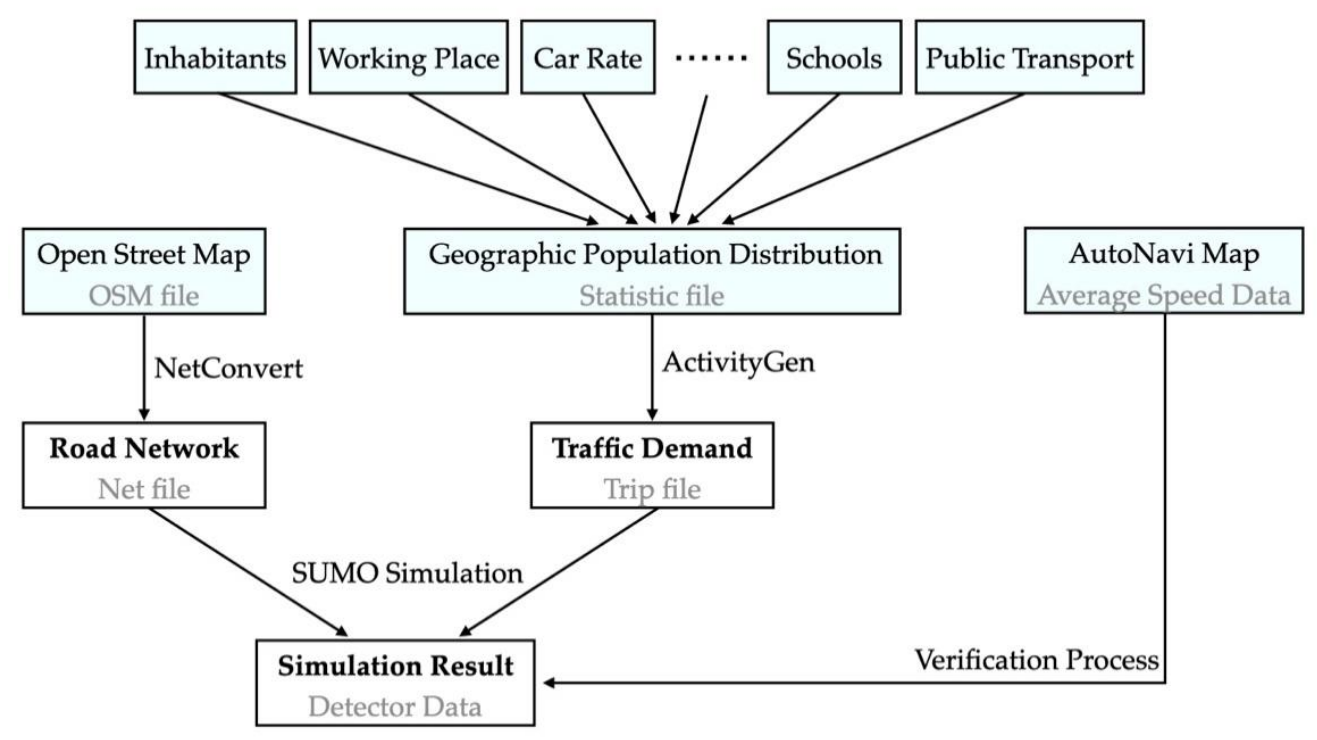

Figure 3. Flow chart of the process of building the simulation. (The data in blue boxes are obtained online).

\section{Results and Discussion}

\subsection{Real-Time Traffic in AutoNavi Map}

To verify the traffic situation created by software, we compared it to the real traffic data. In this article, a macroscopic scale verification method was used because of the limitation of the verification data. AutoNavi map is supported by AutoNavi Software Co., Ltd. (Beijing, China), which provides real-time traffic in three colors. Red indicates congestion and the average speed in this area is less than $5 \mathrm{~km} / \mathrm{h}$, yellow indicates low speed, the average speed is $5-30 \mathrm{~km} / \mathrm{h}$, green indicates smooth traffic with average speeds over $30 \mathrm{~km} / \mathrm{h}$. Compared to the strict data protection guidelines in Europe, the handling of private data in China is much less regulated. Therefore, the collection of real-time traffic data is much easier. For instance, the traffic data of the AutoNavi map are collected in real-time from different sources; $15 \%$ of data are from the traffic control department of the city, mostly their data are from fixed-point detections like camera and induction loops. AutoNavi map users offer the remaining $85 \%$ of data. In most cities, AutoNavi cooperates with taxi companies to gain their FCD. AutoNavi also has a close cooperation with transportation network companies such as Uber and Didi. What is more, as the most popular map app (also Apple Maps' provider), AutoNavi obtain FCD from each user while they are uploading their positions during navigation. After acquired by Alibaba Group, AutoNavi synchronized other staff vehicle FCD such as logistics vehicle data and food delivery data. Though these methods together, AutoNavi get real-time traffic data with high accuracy and fidelity.

\subsection{Comparison of Weekly Data with Simulation}

We selected the eight most representative road sections in the Jianghan Zone (see Figure 4) and recorded their forecasted traffic status in $24 \mathrm{~h}$ from Monday to Sunday. The forecast is provided by the AutoNavi map, and it is based on the data from the same day of the week, and at the same time of the day. For example, the forecasted traffic status of Monday 8:00 is a synthesis of the traffic state at the road section from 8:00 to 9:00 of every Monday. According to the map, we use a different color on behalf of different traffic status: Green for unimpeded, yellow for slow traffic, and red for congestion. For example, the average speed of the vehicles in road Section 1 (verification point 1 ) is lower than $5 \mathrm{~km} / \mathrm{h}$, and the forecasted traffic status of this road section is shown in red. Therefore, the grid at 8:00 on Monday of road Section 1 in Figure 5 is painted in red. The forecasted traffic status of the same road section on Saturday and Sunday are yellow and green, the grids at 8:00 
on Saturday and Sunday of road Section 1 are painted yellow and green, respectively. In these eight road sections, the hourly traffic status of eight verification points is recorded in Figure 5.

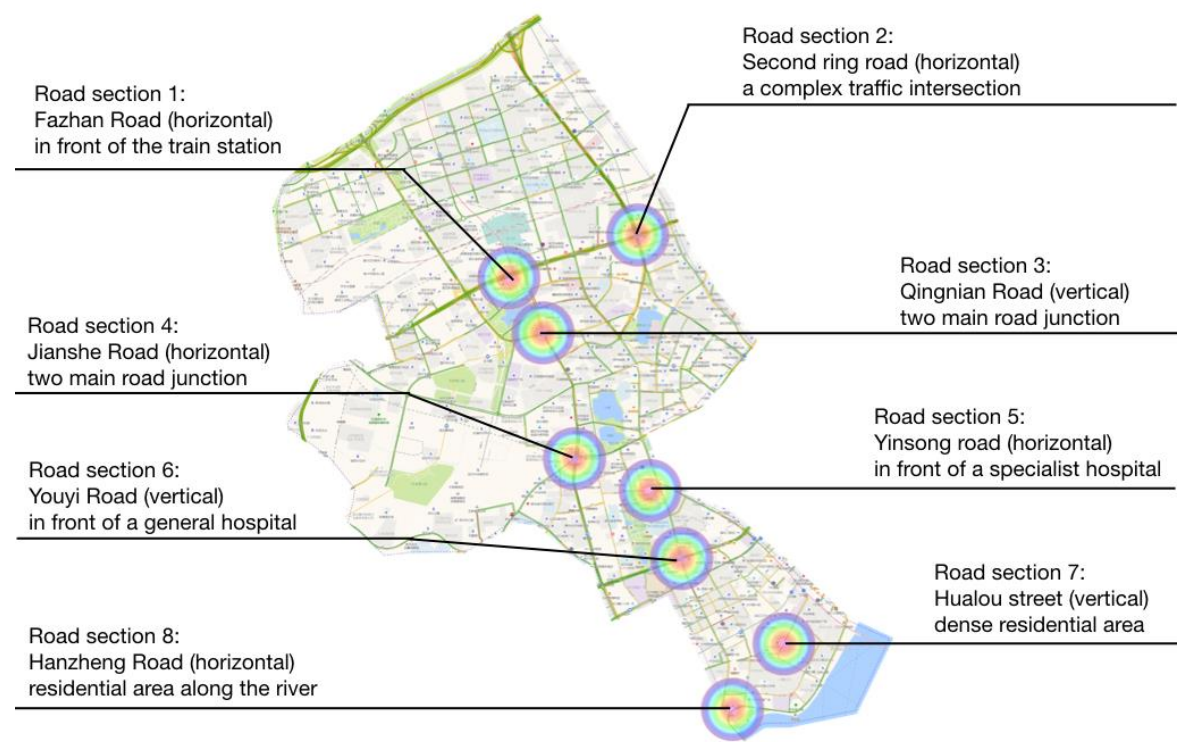

Figure 4. Eight selected road sections' location and features.

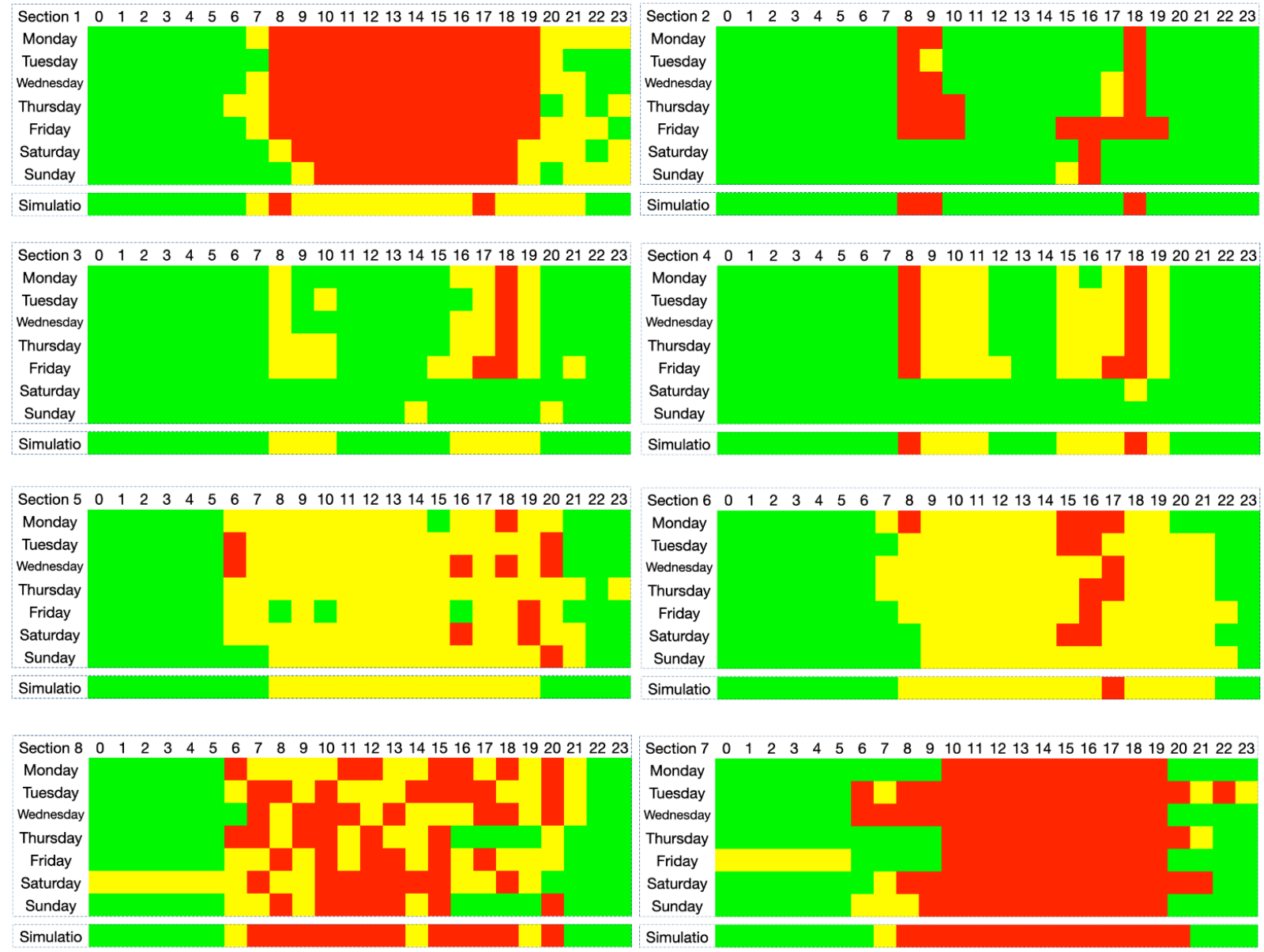

Figure 5. Comparison of simulated traffic and forecasted traffic. 
The hourly simulated traffic status of the 8 verification points is also recorded in Figure 5. The simulation represents a normal working day, the simulation time in seconds is calculated as day time, and if the average speed of vehicles at the road Section 1 between $28,800 \mathrm{~s}$ and $32,400 \mathrm{~s}$ is over $30 \mathrm{~km} / \mathrm{h}$, the grid at 8:00 of simulation of road Section 1 is painted into green. In this way, all hourly simulated traffic status of 8 road sections is recorded in Figure 5.

\section{Results}

In Figure 5, forecasted traffic data are shown from Monday to Sunday vertically, and the last row of each section shows the simulated traffic status. In the 8 road sections, sections 2-4 can represent normal traffic situation in a city, the difference between workdays and weekends are obvious: on weekends, the red and yellow situations (represent traffic jam and slow traffic flow) are apparently less. What is more, in these three sections, peak periods are also outstanding, particularly am 8 and 17 o'clock, the roads carry more traffic pressure. Since ActivityGen does not offer a weekend mode, the simulated traffic is imitating workdays. Therefore, the results of the simulation are simultaneously close to the forecasted traffic situation on workdays is expectable. In road sections $2-4$, the result of the traffic scenario is quite persuasive.

Besides normal road sections, we want to check the accuracy of simulated traffic in special extremely crowded public locations. Therefore, we selected one road section in front of a train station (section 1), two in front of two hospitals separately (sections 5 and 6), and two in densely populated resident areas (sections 7 and 8). Due to the differences in medical systems, family doctors are not common in China, people go to hospitals directly no matter whether they have a serious aliment or not. Moreover, because of cultural differences, people prefer to go to the hospital with their family or friends, which means, half of the people in the hospital are neither medical staff nor patients. All these reasons make hospitals a traffic intensive area, no matter where the hospital is located. In sections 5 and 6 of Figure 5, we can notice that the yellow parts (represent slow traffic) of predicted traffic last longer comparing to normal situations (sections 2-4), and there is no apparent difference between workdays and weekends. The simulation result differs from 6 to 20 o'clock. In addition, actual afternoon rush hour is later than simulated, and also later than normal situations like sections $2-4$, this can be explained by going to the hospital after work.

For some cities, the train station is the busiest area of the city, which is also the case in the Jianghan Zone. In road section 1, traffic jam continues 10 h every day, which shows a relatively large difference from the simulated traffic. The reason could be the passenger flow. Normally the number of passengers leaving from Hankou train station is over 70,000 per day, on special national holidays, the number can be over 140,000 [24]. Nevertheless, the simulation model just considers the working staff of the train station, which are significantly less than the passengers are.

Sections 7 and 8 are example road sections of two dense residential areas. Section 7 is at the edge of residential belts, also connecting the way to Yangtze River, but at the same time, Section 8 is in the middle of a group of dense residential areas and this road section is the only way, which must be passed for several residential quarters. These two sections show longer and heavier jam situations than normal traffic. The simulated traffic status has roughly met the forecasted traffic status from AutoNavi, based on the results from these two sections, we are glad to see ActivityGen can simulate traffic flow in residential areas.

\section{Conclusions}

In this paper, we built a traffic simulation of the Jianghan Zone in Wuhan, China. For a district with 683,500 inhabitants, traffic situations are relatively complex and traffic jams occur often in this busiest area in Wuhan. We simulate the traffic with ActivityGen in SUMO, using geographic population distribution data gathered from public information. To find out the accuracy of the simulated traffic, real-time road condition and traffic prediction 
based on previous data from the same time or each road in this area was compared. In the selected eight representative road sections, most simulated results are close to the predicted traffic based on real data (sections $2-4,7$ and 8 ). In particular areas like hospitals (sections 5 and 6), train station (section 1), the simulated traffic is relatively smoother than real ones. Therefore, further work in enhancing the accuracy of simulated data of ActivityGen can be building new models for special public areas like hospitals and train stations. With more detailed model classification, simulated traffic data can be closer to real conditions.

This article uses a macroscopic verification method for a microscopic traffic simulation in Jianghan Zone of the city of Wuhan. Comparing with our previous experiences of building traffic simulations $[12,13,25,26]$ with more reliable traffic data sources including induction loops data, camera data, OD matrix data, etc., in this article, all the data sources which have been used in building the scenario are all public information gathered from the Internet. Comparing with accurate traffic estimation models using complicated calculation method such as neural network $[27,28]$ and machine learning [29], the estimation method in this work can simulate the average speed of each intersection in the entire city with easy-to-obtain data, and does not require the actual speed of each simulated road section of the whole road network. Moreover, the generated traffic models can be used for assisting road planning, traffic light planning, large-scale event planning, etc.

In an age when privacy information is getting more and more attention and traditional methods of gathering real traffic data are harder to implement and more costly, this paper may offer a new way in traffic flow generation and verification from $100 \%$ public information from the Internet. Further research is planned to improve the accuracy of using geographic population information to generate traffic demand by improving more urban models, including hospitals and railway stations.

Author Contributions: X.M.: conceptualization, data curation, formal analysis, methodology, software, writing and editing. X.H., T.W. and D.S.: conceptualization, project administration and supervision and critical revision. All authors have read and agreed to the published version of the manuscript.

Funding: This research received no external funding.

Data Availability Statement: The data presented in this study are available on request from the corresponding author.

Acknowledgments: We acknowledge support by the Open Access Publication Fund of the University of Duisburg-Essen.

Conflicts of Interest: The authors declare no conflict of interest.

\section{References}

1. ACEA. Economic and Market Report-EU Automotive Industry, Quarter 4 2016. 2016. Available online: https://www.acea.be/ statistics (accessed on 3 December 2020).

2. ACEA. Economic and Market Report-EU Automotive Industry, Quarter 4 2017. 2017. Available online: https://www.acea.be/ statistics (accessed on 3 December 2020).

3. Marmaras, C.; Xydas, E.; Cipcigan, L. Simualtion of electric vehicle driver behavior in road transport and electric power netowrks. Transp. Res. Part C Emerg. Technol. 2017, 80, 239-256. [CrossRef]

4. Pell, A.; Meingast, A.; Schauer, O. Trends in real-time traffic simulation. Transp. Res. Procedia 2017, 25, 1477-1484. [CrossRef]

5. Liang, X.; Du, X.; Wang, G.; Han, Z. A deep reinforcement learning network for traffic light cycle control. IEEE Trans. Veh. Technol. 2019, 68, 1243-1253. [CrossRef]

6. Treiber, M.; Kesting, A. Traffic Flow Dynamics; Springer: Berlin/Heidelberg, Germany, 2013.

7. De Fabritiis, C.; Ragona, R.; Valenti, G. Traffic Estimation and Prediction based on real time floating car data. In Proceedings of the 11th International IEEE Conference on Intelligent Transportation Systems, Beijing, China, 12-15 October 2008.

8. Schaefer, R.-P.; Thiessenhusen, K.-U.; Wagner, P. A traffic information system by means of real-time floating-car data. In Proceedings of the World Congress on Intelligent Transport Systems, Chicago, IL, USA, 14-17 October 2002.

9. Sunderrajan, A.; Viswanathan, V.; Cai, W.; Knoll, A. Traffic State Estimation Using Floating Car Data. Procedia Comput. Sci. 2016, 80, 2008-2018. [CrossRef] 
10. Kastner, K.H.; Keber, R.; Pau, P.; Samal, M. Real-time traffic conditions with SUMO for ITS Austria West. In Proceedings of the Simulation of Urban MObility User Conference, Berlin, Germany, 15-17 May 2013; Springer: Berlin/Heidelberg, Germany, 2013; pp. 146-159.

11. Bieker, L.; Krajzewicz, D.; Morra, A.; Michelacci, C.; Cartolano, F. Traffic simulation for all: A real world traffic scenario from the city of Bologna. In Modeling Mobility with Open Data; Springer: Cham, Switzerland, 2015; pp. 47-60.

12. Ma, X.; Hu, X.; Weber, T.; Schramm, D. Experiences with Establishing a Simulation Scenario of the City of Duisburg with Real Traffic Volume. Appl. Sci. 2021, 11, 1193. [CrossRef]

13. Ma, X.; Hu, X.; Weber, T.; Schramm, D. Traffic Simulation of Future Intelligent Vehicles in Duisburg City Inner Ring. Appl. Sci. 2021, 11, 29. [CrossRef]

14. Shafei, S.; Gu, Z.; Saberi, M. Calibration and validation of a simulation-based dynamic traffic assignment model for a large-scale congested network. Simul. Model. Pract. Theory 2018, 86, 169-186. [CrossRef]

15. Krajzewicz, D.; Erdmann, J.; Behrisch, M.; Bieker, L. Recent Development and Applications of SUMO-Simulation of Urban MObility. Int. J. Adv. Syst. Meas. 2012, 5, 128-138.

16. Codeca, L.; Frank, R.; Engel, T. LuST: A 24-hour Scenario of Luxembourg City for SUMO Traffic simulations. In Proceedings of the SUMO User Conference 2015-Intermodal Simulation for Intermodal Transport, Berlin, Germany, 7-8 May 2015.

17. Asano, Y.; Ito, N.; Inaoka, H.; Imai, T.; Uchitane, T. Traffic Simulation of Kobe-City. In Proceedings of the International Con-ference on Social Modelling and Simulations, Plus Econophysic Colloquium 2014, Kobe, Japan, 4-6 November 2014. [CrossRef]

18. Bian, C.; Yuan, C.; Kuang, W.; Wu, D. Evaluation, classification, and influential factors analysis of traffic congestion in chinese cities using the online map data. Math. Probl. Eng. 2016, 2016, 1693729. [CrossRef]

19. National Bureau of Statistics of China. 2010. Available online: http://www.stats.gov.cn/english/ (accessed on 3 December 2020).

20. Meng, W.; Chen, X. Wuhan Statistic Yearbook 2017. China Statistical Publishing House: China; ISBN 978-7-5037-8197-1.

21. Provincial Transportation Management Bureau. 8 Kinds of Public Transport Modes in Wuhan Are Completed, the Travel Sharing Rate is Reaching 60\%. 2017. Available online: http:/ /www.hbys.gov.cn/ggxw/ywkb/157312.htm (accessed on 3 December 2020).

22. Wuhan Transportation Committee. Statistics on the Total Number of Trips in Wuhan in 2017. 2017. Available online: http: / /jyw.wuhan.gov.cn/Category_137/Index.aspx (accessed on 3 December 2020).

23. Dijkstra, E.W. A note on two problems in connexion with graphs. Numer. Math. 1959, 1, 269-271. [CrossRef]

24. Liu, W.; Zhong, M.; Dai, N.; Chen, H.; Chen, J. Wuhan's Three Major Railway Stations sent 350,000 Passengers on October 2. 2018. Available online: http:/ /hb.people.com.cn/n2/2018/1003/c194063-32122666.html (accessed on 3 December 2020).

25. Ma, X. (2021): Effects of Vehicles with Different Degrees of Automation on Traffic Flow in Urban Areas. Available online: https://duepublico2.uni-due.de/receive/duepublico_mods_00074070.

26. Ma, X.; Hu, X.; Schramm, D. Effects of School Activities on Traffic Flow on the Example of Traffic Scenario from the City Wuhan. In Neue Dimensionen der Mobilität; Springer: Gabler, Wiesbaden, 2020; pp. 153-163.

27. Jiang, B.; Fei, Y. Vehicle Speed Prediction by Two-Level Data Driven Models in Vehicular Networks. IEEE Trans. Intell. Transp. Syst. 2017, 18, 1793-1801. [CrossRef]

28. Habtie, A.B.; Abraham, A.; Midekso, D. Cellular Network Based Real-Time Urban Road Traffic State Estimation Framework Using Neural Network Model Estimation. In Proceedings of the 2015 IEEE Symposium Series on Computational Intelligence, Cape Town, South Africa, 7-10 December 2015; pp. 38-44. [CrossRef]

29. Song, H.; Min, O. Statistical traffic generation methods for urban traffic simulation. In Proceedings of the 201820 th International Conference on Advanced Communication Technology (ICACT), Chuncheon, Korea, 11-14 February 2018; pp. 247-250. [CrossRef] 